\title{
Education Debt and Making a Career Choice in the Public, Private, and Nonprofit Sectors
}

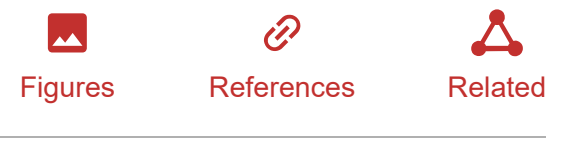

Eddy S. Ng and Jasmine McGinnis Johnson

Published Online: 30 Nov $2017 \mid$

https://doi.org/10.5465/AMBPP.2017.10213abstract

\section{Abstract}

We surveyed a sample of Millennial college seniors who are job seekers to investigate if: (1) education debt discourages students from pursuing (lower paying) public or nonprofit careers, and (2) whether PSM overrides the considerations students might make about entering lower paying sectors (i.e., public and nonprofit sectors) as their education debt rises. To our surprise, we find that education debt is related to a greater propensity to select lower paying public sector careers but not lower paying nonprofit jobs (except for those with high debt loads). Moderate levels of PSM are required for students to select public sector careers and high levels of PSM are required for students to select nonprofit careers with rising education debt. We conclude that individuals with a high debt load may be attracted to public policy setting and select public sector careers, while those who display empathy and compassion are attracted to nonprofit work in service to others.

\section{Academy}

of Management

Proceedings

\section{Proceeding}

Vol. 2017, No. 1

\section{Permissions}

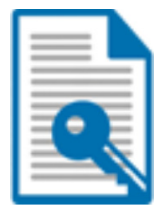

